\title{
MANIPULATOR FOR REMOVING DEBRIS AND OTHER WORK AFTER EXTREME EVENTS
}

\author{
Dr.Victor Balagula, Edvard Smoljanitski, \\ JSC"ARMSTROY"- 73 Volokolamscoe sh. 123424 Moscow, Russia \\ E-mail:info@armstroy.com \\ Dr.Oleg Sanko, \\ Moscow State Civil-Engineering University, \\ 26 Jaroslavskoe sh.129337 Moscow, Russia \\ E-mail:osanko@mail.ru
}

\begin{abstract}
This paper presents a description of the basic model of a manipulator for removing debris and work after extreme events. The manipulator consists of different tools which can make all necessary operations to save people in extreme situations.
\end{abstract}

Keywords: manipulator, blockage, debris, motor-powered grab, two-part bucket.

\section{INTRODUCTION}

In addition to natural disasters, such as earthquakes, floods and volcanic eruptions, a growing number of technology-induced accidents occur every year - fires, industrial accidents, and acts of terrorism. As a result of these extreme events, residential and industrial buildings collapse causing loss of numerous human lives. The problems encountered in demolishing such buildings rapidly and effectively bear resemblance to the problems of demolishing old buildings in general.

The above circumstances have created a need for highly effective manipulators capable of removing the debris.

The acuteness of the problem is illustrated by statistical data showing that only $50 \%$ of those trapped in a building at the time of the accident are fatally injured. Nevertheless, only about $30 \%$ of those who survive the collapse of the building are rescued, due to the fact that aid reaches the rest of the survivors too late, that is 3-5 days after the accident.

In Russia, rescue operations are conducted by rescue squads of the Emergency Service, who have only mechanical tools at their disposal. This means that life-saving operations are prolonged and consequently not very efficient. Construction machines used for rescue operations, for instance cranes on truck-type chassis and special chassis, bulldozers, loaders and excavators, are not effective enough, as it is impossible to have several types of machines removing the debris simultaneously in the same zone.

Among machines analogical to these one could mention the German hydraulic excavators UB 1236 by NOBAS GmbH Nordhauser, which are fitted with a tool kit for carrying out various technical operations to remove the rubble.

However, machines working successfully on building sites are not suited for fast rescue operations as the high requirements for mobility exclude the use of crawler mounting machines. Thus, the necessity of creating a special mobile manipulator for the removal of debris has become obvious in Russia.

The main tasks to be solved before design work can start are as follows:

- Determination of optimal technology for the management of work on removing debris;

- Determination of optimal ways and means of completely mechanizing the removal of debris for the purpose of rescuing people;

- Determination of the power and speed characteristics of operating devices as well as determination of how to combine them in the work process;

- Design of hydraulic drive and electro-hydraulic control systems, enabling the steering of the operations of the manipulator both from the operator's cabin and on-site.

\section{UNDERLYING PHILOSOPHY}

The manipulator should ensure the carrying-out of the following kinds of operations:

Lifting operations

- Vertical lifting of weights not less than 10 tons

- Vertical lifting of debris not less than $3.2 \mathrm{~m} 3$

Digging operations

- Removal of soil above, below and at the same level as the machine stands (bucket capacity $1.0 \mathrm{M} 3$, stroke not less than $3.0 \mathrm{M}$ )

- Digging and arm rotation at digging depth not less than $3.0 \mathrm{M}$ with maximum digging radius not less than $10 \mathrm{M}$

- Removal of soil locally without mixing the layers in the pit or in the bucket.

Work on bringing down walls and hoisting debris in the zone of crane operation

- Nominal pull of winch not less than $3.0 \mathrm{~T}$

Speed not less than $60 \mathrm{~km} / \mathrm{h}$

The manipulator runs on pneumatic wheels. The dimensions of the manipulator should permit its free loading in the transport plane Iljushin-76. 


\section{MACHINE DESIGN}

In fig. 1 the manipulator is shown on a KAMAZ truck chassis of Russian manufacture. The design of the manipulator includes: a rotating platform (1), a two-section telescopic boom (2) with a cylinder (3), hydraulic winch (4) for the lifting of loads. On the rotating platform there is a cabin (5) which can be elevated and an extracting winch (6). The aim of the winch is to bring down walls and hoist debris.

The arm of the drag shovel (7) and its inclination cylinder are fixed to the bottom of the telescopic boom section. The bucket of the drag shovel consists of two parts and can be opened by an additional cylinder.

When stationary, the arm of the drag shovel is pressed against the mobile lower boom section and does not disturb its extracting and retracting movement during crane operation. The rotating twopart bucket may dig thanks to both the turning arm and the retractable lower boom section.

A motor-powered grab (8) is fastened to the hook of the crane. It is intended for gripping, keeping and carrying large building elements of up to 10 tons. The control of the grab can be executed by the operator in the cabin or by a worker next to the grab. Energy can be supplied for the grab by a basic hydraulic system or by an independent pump station.

Technical data

Maximum load moment, $\mathrm{t} x \mathrm{~m} \quad-80$

Maximum lifting capacity, $\mathrm{t} \quad-10$

Maximum boom radius,

ensuring lifting capacity $10 \mathrm{t}, \mathrm{m} \quad-8$

Lifting capacity of the grab, $\mathrm{t} \quad-10$

Bucket capacity of the grab, $\mathrm{m} 3 \quad-3.2$

Maximum dumping radius, $\mathrm{m} \quad-10$

Maximum digging depth, $\mathrm{m} \quad-3.5$

Maximum digging force, $\mathrm{m} \quad-\quad 8$

Maximum force of extracting winch, $\mathrm{t}-3$

Overall dimensions, $\mathrm{m}$ :

Length $\quad-9.5$

Width -2.5

Height -3.2

Working mass, $\mathrm{t}-25$ 


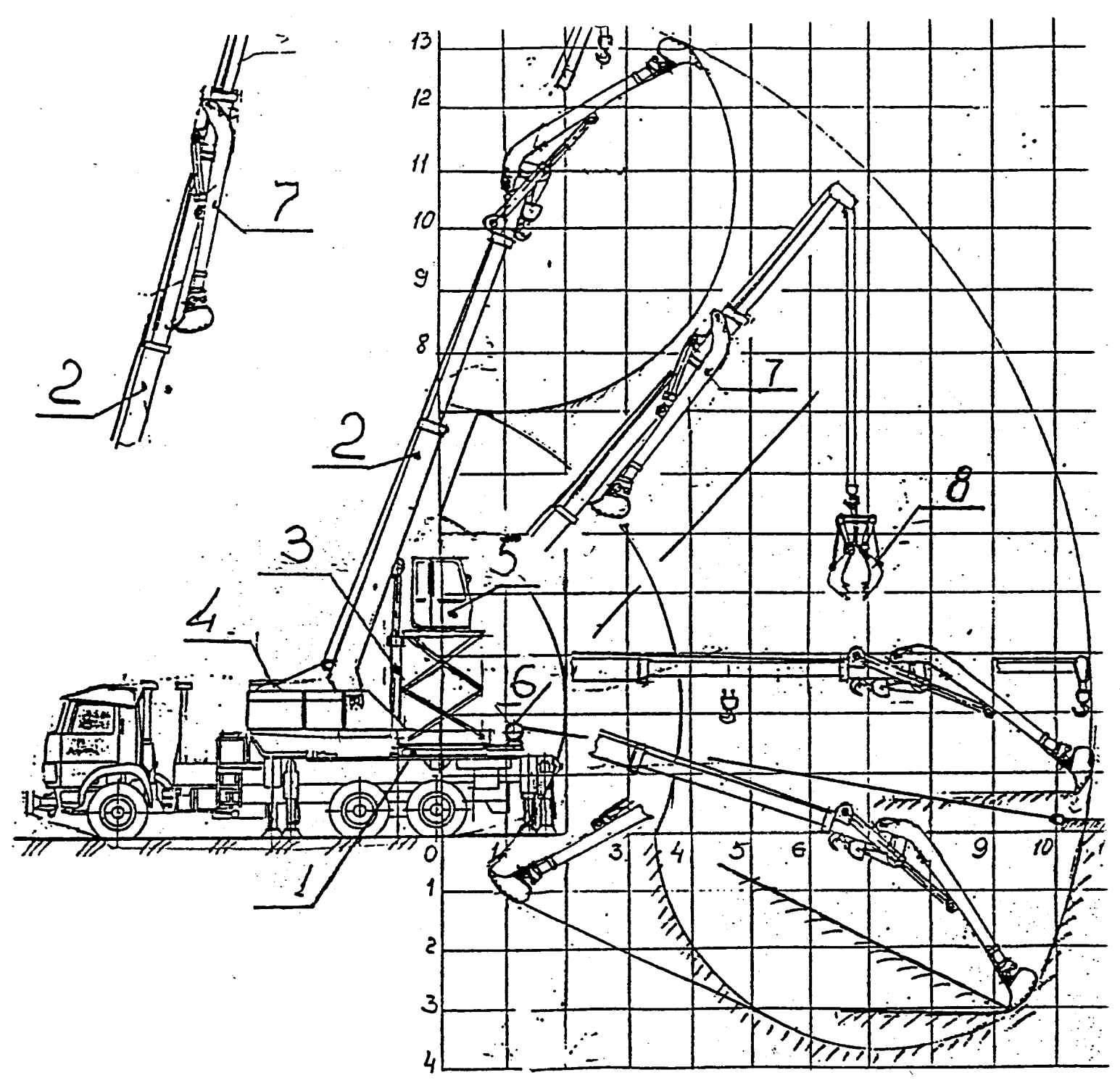

